\title{
Rejecting white distraction: a critique of the white logic and white methods in academic
} publishing

Shantel Gabrieal Buggsa1, Jennifer Patrice Simsb2 and Rory Kramerc3

a Department of Sociology, Florida State University, Tallahassee, USA

b Department of Sociology, University of Alabama-Hunstsville, Huntsville, USA

c Department of Sociology \& Criminology, Villanova University, Villanova, USA

\begin{abstract}
This critical reply engages in a critique of the prominence of "white logic" and "white methods" (Zuberi and Bonilla-Silva 2008) in academic publishing. We assess how the construction and proliferation of white knowledge(s) shapes analysis and interpretation, argumentation, peer review, and ultimately, publication. We call for a rejection of what we name "white distraction" and encourage the academic community to move toward more inclusive and decolonial modes of thinking, reviewing, and publishing.
\end{abstract}

ARTICLE HISTORY Received 01 October 2019; Accepted 12 November 2019

\section{KEYWORDS}

white logic, white methods, decolonizing the academy, race, racism, Black feminist theory

1 Shantel G. Buggs: sbuggs@fsu.edu, @sgbuggs (Twitter)

2 Jennifer P. Sims: jennifer.sims@uah.edu, @ RavenclawSoc23 (Twitter)

3 Rory Kramer: rory.kramer@villanova.edu, @ rory_kramer (Twitter) 
Toni Morrison (1975) famously argued that "the function, the very serious function of racism is distraction." This quote is often ended here and then misconstrued to imply that racism itself is a distraction from the root problem that deserves attention. Morrison's more powerful point, though, is in the later part of the full quote where she observes that "Somebody says you have no language and you spend twenty years proving you do." This is the real distraction-the compulsion to shift attention and efforts away from more critical matters and engage in the futile effort of attempting to prove one's competence to people who are ideologically committed to mis(re)presenting you.

This symposium is such a distraction. The article1 at the center of it was published “online first” by Ethnic and Racial Studies (ERS) on July 18, 2019. A little over a week later, scholars of racism, most of them women of colour, began to discuss via Twitter what many viewed as empirical, methodological, and theoretical errors. Concurrent with the posting of an open letter to the journal signed by 176 scholars and media coverage in The Chronicle of Higher Education, on July 30, 2019, ERS announced on Twitter that the article went through double blind peer review, "major revisions," and was in fact a "review article" not an empirical study. The journal's series of tweets also noted that the article was part of the journal's regular series of debates and symposia. Traditionally, though, symposia are planned months in advance and the call for papers is published as an emailable PDF, usually at the same time as the article. However, in this case, the symposium announcement only came after the article was publicly criticized and we are not aware of any call for papers posted other than via Twitter and mentioned in The Chronicle.

The attempt to placate and distract could not be clearer; therefore this symposium puts scholars of racism in a classic no win position. Either boycott the symposium on the grounds that 
"part of self-care is not arguing with people who are committed to misunderstanding you" (Akanbi 2017) but leave the article's inaccuracies uncorrected; or reply to the symposium thereby giving "spontaneous consent" (Fanon 2004) to our own subjugation by legitimating the original article.

As academics who value scientific enterprise and bringing traditionally silenced perspectives "from the margin to the center" (hooks 2000), we were uncomfortable with the first option. Nevertheless, the option of a traditional reply was also undesirable. How should one academically engage an article full of non-empirical claims that demonstrates a lack of knowledge of the field? How does one demonstrate Black activists' and scholars' legitimacy and explain the goals, tactics, and theoretical concepts to those unwilling to see beyond the veil? Where do we begin a reply to those who bluntly assert that we do not competently interpret the world simply because we interpret it outside of the hegemonic white cisheteropatriarchal framework that falsely claims objectivity?

We reject these as the terms of engagement for it is the "one more thing" Morrison warns racism always demands. To borrow liberally from Du Bois (1994), white (and white-masked) academics like the article's author and his supporters approached BLM in a half-hesitant sort of way, eyeing it curiously or compassionately, and then, instead of saying directly, "How does it feel to be a problem[atic social movement]?" said, "I know an excellent social movement named The Rainbow Coalition in my town;” or, "I camped at Zuccotti Park;” or, "Do not Trump’s tweets make your blood boil?" At these, we are too tired to smile, or feign interest, or reduce our boiling to a simmer, as the occasion might require. To the real question, "how does it feel to be a problem[atic social movement]?" we follow Du Bois and answer not a word. The very invitation 
itself stems from the dominant "white logic" that "grants centrality to the knowledge, history, science, and culture of elite white men" (Zuberi and Bonilla-Silva 2008: 17).

Therefore, in this paper we opt for a third option - to explain why we reject the distraction of a traditional critical academic reply in this specific case. This is not to reject the fundamental value of debate and inquiry, but rather to highlight how the journal review and publication processes, if not carefully considered reflexively, will reinforce the structures and methods of academia that reify racism and white supremacy (Zuberi and Bonilla-Silva 2008). Those white methods operate based on "modes of knowing" rooted in oppression (Sharpe 2014). Therefore, we instead discuss the failures of the peer review process that flow from "white logic," question the use of a symposia as a response to the serious criticism of the publication of said article by a leading journal of race and racism, and conclude with an invitation to reject the distraction of defending people of colour against white male epistemologies.

Omissions, misrepresentations, and knowledge by fiat

Zuleyka Zuvallos (2019) rhetorically asked "Why does an inexperienced white man, with a history of right-wing leaning pop culture articles (including similar uninformed critiques of Black women and BLM), pass peer review with something far removed from the 'objectivity' and ethics demanded of Black sociologists and other people of colour?" We answer that it is when the peer review process neglects its scientific aims and instead functions as a tool to promote and legitimate white male epistemologies. Usually ERS reviewers can be counted upon to provide a thorough assessment of a manuscript's theoretical basis and methodological soundness; despite ERS's claims that the article in question went through peer review including 
major revisions, it is clear that the process missed numerous errors, elisions, and methodological fatal flaws.

For example, ERS claims that the article was a "review" of social scientific research on Black Lives Matter, yet it does not include any discussion of relevant literature from academic journals such as Du Bois Review, Ethnicities, Mobilization, Social Movements Studies, or Sociology of Race and Ethnicity. Most astonishingly, the article also fails to review any work on BLM from the very journal in which it is published. This is despite the fact that ERS previously published an entire symposium on Black Lives Matter in 2017. The citation and discussion of work from off-subject journals like The Concord Saunterer: A Journal of Thoreau Studies and from "viral" internet sources like Medium in lieu of engagement with the literature from leading academic outlets betray the claim that the article is a systematic review of the academic literature on the topic and of the breadth of organizing under the banner of Black Lives Matter. It is instead a discussion of cherry-picked works that suit the author's ideological agenda.

More to the point, any expert in the field of race-based social movements should have noticed the complete lack of engagement with the field immediately. From personal experience receiving and writing reviews for $E R S$, we know first-hand that $E R S$ reviewers routinely suggest other works on the topic that should be included in the discussion, as is common. While jokes abound about this practice simply being a reviewer attempting to increase their own citation count, the practice is actually quite beneficial to introducing scholars, especially early career scholars, to new and pertinent research in their subfield. How is it, then, that none of the reviewers of the article in question thought to suggest even a single article published in the premier race and social movements journals listed above? Or, if such literature was suggested, 
how did the editors accept the resubmission for publication despite it failing to incorporate said hypothetical suggestion?

We ask the above rhetorical questions not in the hopes that they are answered in reference to this specific article or even this specific journal. Instead, these questions demonstrate the continued practice of granting authority and platform to even the most poorquality white and male-centered work in contrast to the enforcement of rigorous standards for others.

Another issue that reviewers routinely take note of is when an author demonstrates misunderstanding of or misrepresents the nature of the works that are discussed. Here too, however, the ERS reviewers failed to apply the typical sharp review of the work that is discussed in the article for a mindboggling amount of it is a parochial mis-portrayal. For just a few examples: The author's use of Fannie Lou Hamer is a blatant misrepresentation of her activism and her critique of racism. His criticism of intersectionality for not grappling with class adequately likewise is a complete misrepresentation of Patricia Hill Collins, Kimberlé Crenshaw, and all of the other scholars of intersectionality that he chose to not cite who have, from the beginning, included (Black people's) class in their analyses. One such scholar is further misrepresented when his claim that Cathy Cohen - the author of a pioneering study of class conflict within Black movements and politics (Cohen 1999) —leads readers away from class conflict is directly contradicted in the very interview with her that he cites. In that interview she raises Fight for \$15 as an intersectional movement of race, class, and gender, and discusses the movement for trans-inclusivity explicitly because of the class dynamic within it. The assertion that the Combahee River Collective (CRC) accomplished little in terms of their radical vision is a similar misrepresentation, promoting a problematic logic of how to measure "successful" 
organizing based on how many “average Americans" know of an organization’s existence instead of acknowledging the fact that CRC affiliates were active in broader coalitions to address desegregation, police brutality, labor inequality, and a lack of attention to the disturbing Roxbury murders of 12 Black women between January and May 1979. That Du Bois' concept of "wages of whiteness" would be employed to support an argument for centering poor whites over Blacks in a movement is literally laughable to anyone who has actually read more than the abridged version of Chapter 1 of The Souls of Black Folks. In short, the article not only mis-cites and misrepresents current scholars and organizers, it also grossly misrepresents former civil rights activists and classic Black sociological theory.

Distraction and disrespect via elision continue throughout the article. However, that is not our principle concern. Our concern is to wonder how ERS's supposed expert reviewers themselves had such poor knowledge of Hamer, Collins, Crenshaw, Cohen, Ransby, the CRC and others that an author's thinly veiled visceral disgust with Black women for not centering poor whites was accepted as a scholarly assessment of their (albeit largely un- or under-cited) works? Or again, if this critique did surface during the "major revision" process, why did the editors feel it okay to move forward to publication without it being addressed?

Finally, as a "review," the article in question is not based on empirical analysis. The bold assertion, early in the article, that Black women's "political power as organizers was in no way correlated to the revolutionary agenda they articulated" is therefore wildly inappropriate and completely unproven. While it will surely be argued that this is simple semantics, the fact that reviewers, and later editors, did not object to the statistical language speaks volumes. For whereas $E R S$ has asked authors of anti-racist work to run entirely new statistical models to be sure that their claims of correlation were robust, no flags were raised (or raised flags were 
ignored) when a paper denigrating Black feminist activism and scholarship makes such claims based on no data at all. In publishing this article, therefore, ERS is complicit in the perpetuation of the white logic that traditional white male-centered ideas about the inherent deficiency of racial and gender minorities is objective knowledge while claims to the contrary must be tested and proved via heavily scrutinized scientific investigation.

To us, the above is evidence that the problem is not an individual scholar and his individual interpretation of selected works. The problem is a peer review process that has not adequately addressed the racial structure of knowledge. Decolonizing the academy requires not only the inclusion of historically delegitimized scholarship from marginalized scholars, but also revised review processes that incorporate the scholarly work, traditions, theorizing, and epistemology of subaltern/marginalized peoples that have always existed. While ERS should be commended for making strides with regard to the former, the six-month receipt, review, revision, page proofing, and publishing of this article represents a failure of the latter. The article's speedy publication illustrates traditional gatekeeping (or should we say glass escalatoring) which accidentally or perhaps intentionally elevates white male-centered colonial opinions to the level of scientific scholarship.

As noted in our introduction, this symposium attempts to further legitimate the practice of male, white-centered knowledge creation by fiat. If ERS truly seeks to engage scholarship and debate around contemporary issues in race and racism, then why choose a one-off article that lacked both theoretical sophistication and empirical data from which to springboard such debate? Why not invite research on, and theoretical analysis of, the rise of white supremacist murderers radicalized via online forums, Russian cyber-attacks that rely on racial appeals on elections outside of Russia, the rise of deep fakes, credit card breaches, right wing attacks on professors 
via online spaces, or racial differences in experiences of surveillance and facial recognition? Why not a symposium on the timely issue of racial inequality becoming literally encoded into society centered on the three new books on race and technology by Ruha Benjamin (2019) and Safiya Nobel (2018)? Or, if the editors of ERS felt strongly that BLM is important enough to warrant a second symposium, why not center it around deeply researched work like Jennifer Cobbina's Hands Up Don't Shoot (2019), Andrea Boyles'You Can't Stop the Revolution (2019), or Barbara Ransby's Making All Black Lives Matter (2018)? The answer hangs silently in the air yet we will pronounce it audibly: because those works reject white male-centered epistemology.

\section{Putting an End to White Distractions}

This symposium invited scholars of colour and scholars who have spent years studying racism and/or social movements to reply to a piece that shows no prior knowledge of the majority of that work and shows nothing but contempt for the few works that it does consider. At its core, this is framing the debate around white ignorance (Mueller 2018). Only a debate grounded in white ignorance and a white epistemology would demand that scholars of colour defend their research and claims yet again. We are tired of the distraction of justifying anti-racist, decolonized epistemologies to those who seek to maintain traditional colonial knowledge traditions. Not just because it is tiresome to constantly point out the decades of work that are routinely ignored or misrepresented by scholars who operate from a white logic framework, but more importantly because it represents a 21 st century mechanism to suppress the work of scholars of colour who challenge white logic and white methods.

As we write these words, we are mindful of what we are being distracted from doing. The syllabi and assignments not being updated, the course prep and grading delayed. The regression 
models not being run, the interviews not being undertaken or coded, the participant observation skipped, the pile of books and articles not being read, the peer reviews not being completed, the mentoring meetings skipped or rushed. It is back to these critical efforts that we will soon return our attention. Having been but momentarily distracted, we will return to doing the research and writing the sociology that will push the academy away from its white supremacist cisheteropatriarchal roots, not continue to legitimate it by engaging on its colonial terms. We are going to conduct experiments that reveal the role of hairstyle in racial perception and advocate to eradicate racist workplace bans on hairstyle. We are going to assess the impact of microaggressions on women of colour and nonbinary people of colour's academic job market experiences. We are going to gather oral histories of Black students' experiences navigating place and community at PWIs in the South. We are going to finish writing the grant application to fund a sixth wave of a longitudinal survey. In short, we will reject the white distraction and invite the editors, authors, and readers of ERS to join us.

\section{Conclusion}

As we were finishing this piece, we were informed that normal editorial process dictates that the author of the original piece is invited to reply to these responses. While we do wonder how standard this whole process has actually been, we instead want to end by questioning what work "normal editorial process" is doing here. In this case, this means that the discussion of a Black, queer, women- and femme-led movement is bookended by thoughts that come without a clear epistemology about the use of evidence or systematic analytic process. This lack of a systematic methodology is exactly the critique levied against intersectional work, Patricia Hill Collin's Afrocentric epistemology and other efforts by non-white scholars to either move away 
from white logics and methods (Zuberi and Bonilla-Silva 2008) or to decolonize the academy (Go 2017; Hall and Tandon 2017; Rodriguez 2018). It also means that the final word goes to he who has already once published his view that empowered Black voices should not be "prioritized." Standard processes are often the way for structurally empowered individuals and groups to justify the exclusion and/or mistreatment of those at the racial periphery, as critical race scholars have detailed at length, including specifically with regard to Black social movements (Bracey 2015).

We thus invite ERS to reconsider whose legitimacy should be interrogated, whose should be taken for granted, and why they published a piece that primarily attacks Black women activists and scholars for a supposed review of the limits and possibilities of Black Lives Matter. We encourage ERS to reimagine what a decolonized version of dialogue about a topic would look like as opposed to relying on logics and procedures born with and from racist, heterosexist, and capitalist modes of knowledge production. We ask that all journals hold reviewers accountable for being knowledgeable enough about the field to be able to identify when a manuscript omits and misrepresents the scholarship in the field and/or makes empirical claims without data or analysis. We also expect everyone who submits to a journal to be held to consistent standards during the submission, review, and publication process.

To be incredibly clear, it is ERS's decision to publish the article and host the symposium to which we are reluctantly responding that we find most concerning, not that the author believes or argues for something with which we "disagree." This symposium, too, is concerning as it fundamentally reinforces what Patricia Hill Collins described decades ago as "Eurocentric knowledge validation processes" (Collins 1999, 253), and ERS is not alone in this practice. In the last few years we have seen prominent journals publish "peer-reviewed" articles arguing that 
colonialism was beneficial, that Jewish people's "evolution" is at fault for declining white ethnonationalism, that criticism of a "father of science" who experimented on enslaved African women is not fair, among others. It is past time for scholars and gatekeepers in these fields to reject the traditions born from a racist legacy of colonial fantasy and more fully embrace the scholarship and epistemologies that were born in the critical responses. How should ERS and other journals rethink their review processes to ensure that they stop replicating a colonial, white-centering epistemology and cease participating in the minimizing of "white people's active interest in reproducing the racist status quo" (Milazzo 2017)? We have taken this brief time and these journal pages to focus on the role of journals in institutionalizing distracting scholars of racism. We hope that $E R S$ and other journals have the humility and commitment to anti-racist scholarship to listen.

\section{ACKNOWLEDGEMENTS}

The authors are grateful to Whitney Laster Pirtle, Zawadi Rucks-Ahidiana, Blu Buchanan, and Glenn E. Bracey II for their multiple rounds of feedback on this piece.

\section{ENDNOTES}

1. We have intentionally decided not to cite the specific article in this piece so as to not inflate citation counts as citations are political. Further, a primary criticism of the piece is its lack of citations to important literature and we aim to avoid what Derrick and Benneworth (2019) call "grimpact."

\section{REFERENCES}

Akanbi, Ayishat A. (@Ayishat_Akanbi).2017. "Self care is also not arguing with people who are committed to misunderstanding you." [Twitter Post]. Retrieved from https://twitter.com/ayishat_akanbi/status/917431189975326721?s=21 
Benjamin, Ruha. 2019. Race After Technology: Abolitionist Tools for the New Jim Code. New York: Polity.

Benjamin, Ruha (ed). 2019. Captivating Technology: Race, Carceral Technoscience, and Liberatory Imagination in Everyday Life. Duke University Press.

Boyles, Andrea S. 2019. You Can't Stop the Revolution: Community Disorder and Social Ties in Post-Ferguson America. University of California Press.

Bracey II, Glenn E. 2015. "Black Movements Need Black Theorizing: Exposing Implicit Whiteness in Political Process Theory." Sociological Focus, 49(1); 11-27.

Cobbina, Jennifer E. 2019. Hands Up, Don't Shoot: Why the Protests in Ferguson and Baltimore Matter, and How They Changed America. New York University Press.

Cohen, Cathy J. 1999. The Boundaries of Blackness: AIDs and the Breakdown of Black Politics. University of Chicago Press.

Collins, Patricia Hill. 1999. Black Feminist Thought: Knowledge, Consciousness, and the Politics of Empowerment, Revised 10th Anniversary, 2nd Edition. London: Routledge.

Derrick, Gemma and Paul Benneworth. "Grimpact--Time to acknowledge the dark side of the impact agenda.” London School of Economics (LSE) Impact Blog, 28 May 2019. https://blogs.1se.ac.uk/impactofsocialsciences/2019/05/28/grimpact-time-to-acknowledge-thedark-side-of-the-impact-agenda/

Du Bois, W. E. B. 1994 [1903]. The Souls of Black Folk. New York: Dover Publications. Fanon, Frantz. 2004 [1963]. The Wretched of the Earth. Trans. Richard Philcox. New York: Grove Press.

Go, Julian. 2017. "Decolonizing Sociology: Epistemic Inequality and Sociological Thought." Social Problems, 64(2); 194-199.

Hall, Budd L. and Rajesh Tandon. 2017. "Decolonization of knowledge, epistemicide, participatory research and higher education." Research for All, 1(1); 6-19.

hooks, bell. 2000. Feminist Theory: From Margin to Center, 2nd ed. Cambridge, MA: South End Press Classics.

Milazzo, Marzia. 2017. “On White Ignorance, White Shame, and Other Pitfalls in Critical Philosophy of Race.” Journal of Applied Philosophy, 34(4); 557-572.

Morrison, Toni. 1975. "A Humanist View" (speech, Portland, Oregon, May 30). Black Studies Center public dialogue, Pt. 2. https://pdxscholar.library.pdx.edu/orspeakers/90/

Mueller, Jennifer C. 2018. "Advancing a sociology of ignorance in the study of racism and racial non-knowing." Sociology Compass, 12(8); 1-22. 
Ransby, Barbara. 2018. Making All Black Lives Matter: Reimagining Freedom in the TwentyFirst Century. University of California Press.

Rodríguez, Clelia O. 2018. Decolonizing Academia: Poverty, Oppression and Pain. Winnipeg, Manitoba: Fernwood Publishing.

Sharpe, Christina. "Black Life, Annotated." The New Inquiry, 8 August 2014.

https://thenewinquiry.com/black-life-annotated/

Zuvallos, Zuleyka. "Whitewashing Race Studies.” The Other Sociologist, 29 July 2019.

https://othersociologist.com/2019/07/29/whitewashing-race-studies

Zuberi, Tukufu, and Eduardo Bonilla-Silva (eds). 2008. White Logic, White Methods: Racism and Methodology. Lanham, MA: Rowman \& Littlefield. 